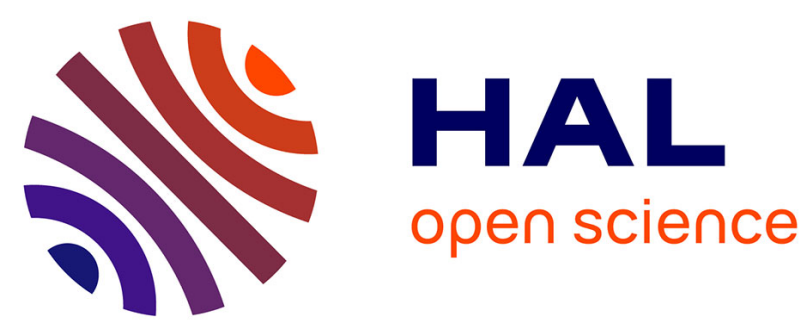

\title{
Molecular Design and Control Over the Morphology of Self-Assembled Films on Ionic Substrates
}

\author{
Ania Amrous, Franck Bocquet, Laurent Nony, Franck Para, Christian \\ Loppacher, Simon Lamare, Frank Palmino, Frederic Cherioux, David Gao, \\ Filippo Federici Canova, et al.
}

\section{To cite this version:}

Ania Amrous, Franck Bocquet, Laurent Nony, Franck Para, Christian Loppacher, et al.. Molecular Design and Control Over the Morphology of Self-Assembled Films on Ionic Substrates. Advanced Materials Interfaces, 2014, 1 (9), pp.1400414. 10.1002/admi.201400414 . hal-01702354

\section{HAL Id: hal-01702354 https://hal.science/hal-01702354}

Submitted on 15 Feb 2018

HAL is a multi-disciplinary open access archive for the deposit and dissemination of scientific research documents, whether they are published or not. The documents may come from teaching and research institutions in France or abroad, or from public or private research centers.
L'archive ouverte pluridisciplinaire HAL, est destinée au dépôt et à la diffusion de documents scientifiques de niveau recherche, publiés ou non, émanant des établissements d'enseignement et de recherche français ou étrangers, des laboratoires publics ou privés. 


\title{
Molecular Design and Control Over the Morphology of Self-Assembled Films on lonic Substrates
}

\author{
Ania Amrous, Franck Bocquet, Laurent Nony, Franck Para, Christian Loppacher,* \\ Simon Lamare, Frank Palmino, Fréderic Cherioux, David Z. Gao,* Filippo Federici Canova, \\ Matthew B. Watkins, and Alexander L. Shluger
}

Achieving control over formation of molecular films on insulating substrates is important for designing novel 2D functional materials and devices. To study the main factors governing successful control, organic molecules with interchangeable polar functional groups, a variable length aromatic body, and flexible hydrocarbon chains are designed, synthesized and then deposited on the (001) surfaces of bulk sodium chloride, potassium chloride, and rubidium chloride. The deposited structures are imaged using noncontact atomic force microscopy and modeled using density functional theory. The results show that it is possible to form large-scale, highly ordered, 2D, porous molecular domains ( $>10^{4}$ pores), which are stable at room temperature, and to control the size of the 2D pores. Alternatively, it is possible to form line structures or droplets (through molecular dewetting) by altering the molecular structure or changing the substrate lattice constant. Theoretical calculations explain the balance of the molecule-molecule and molecule-surface interactions and the structure and thermodynamic stability of the grown films.

\section{Introduction}

Thin films composed of organic molecules are of wide interest in surface science, catalysis, ${ }^{[1]}$ lubrication, ${ }^{[2,3]}$ and molecular electronics. ${ }^{[4-6]}$ Controlling the structure and properties of these films at molecular scale is of critical importance for designing novel functionalities of the overall material, which are

A. Amrous, Dr. F. Bocquet, Dr. L. Nony,

F. Para, Prof. C. Loppacher

Aix-Marseille Université

CNRS, IM2NP UMR 7334

13397, Marseille, France

E-mail: christian.loppacher@im2np.fr

S. Lamare, Prof. F. Palmino, Dr. F. Cherioux Institut FEMTO-ST, Université de Franche-Comté

CNRS, ENSMM

Besançon, France

D. Z. Gao, Dr. F. Federici Canova,

Dr. M. B. Watkins, Prof. A. L. Shluger

Department of Physics and Astronomy

University College London

Gower Street, London, WC1E 6BT, UK

E-mail: david.gao.10@ucl.ac.uk

F. Federici Canova, Prof. A. L. Shluger

WPI-Advanced Institute for Materials Research

Tohoku University

2-1-1 Katahira, Aoba-ku, Sendai 980-8577, Japan

DOI: 10.1002/admi.201400414 determined by the substrate as well as the film. A high level of control over various molecular structures has been achieved on metal surfaces. For example, functional end groups have been incorporated into porphyrin molecules in order to fabricate 1D or 2D structures, ${ }^{[7]}$ highly ordered mixed phases of different molecules have been created, ${ }^{[8,9]}$ and polymerization has been induced to guarantee a good lateral conductivity in these films. ${ }^{[10-14]}$ Highly controlled molecular self-assembly on semiconductors has also been demonstrated. ${ }^{[15]}$ However, applications, such as optoelectronic and molecular devices, require the use of bulk insulators in order to avoid the coupling of molecular orbitals with the surface. ${ }^{[16]}$ The formation of organic layers on insulators has been achieved in the past by either strengthening the molecule-surface $(\mathrm{M}-\mathrm{S})$ interaction by means of appropriate anchoring groups, ${ }^{[17,18]}$ or by reinforcing the molecule-molecule (M-M) interaction. ${ }^{[19,20]}$ Several attempts have also been made to influence the balance between $\mathrm{M}-\mathrm{S}$ and $\mathrm{M}-\mathrm{M}$ interactions. ${ }^{[21-23]}$ However, achieving control over structural characteristics of large-scale supramolecular networks, such as e.g., pore size, proved challenging.

One of the main difficulties for achieving self-assembly on insulating surfaces is concerned with relatively weak $\mathrm{M}-\mathrm{S}$ interactions that lead to molecular diffusion and the dewetting of molecular layers. ${ }^{[2,25]}$ For instance, $\pi$-stacking $\mathrm{M}-\mathrm{M}$ interactions can dominate weak $\mathrm{M}-\mathrm{S}$ interactions. ${ }^{[2,25]}$ Two main strategies have been proposed in order to circumvent these problems. The first one concerns substrate choice and modification. Surface patterning of ionic surfaces by e-beam irradiation has been shown to limit diffusion ${ }^{[25]}$ while surfaces with high surface energy, such as calcite, prohibit dewetting. ${ }^{[26]}$ A second strategy involves educated molecular design. Some molecules are able to form wire structures through $\pi$-stacking, ${ }^{[27,28]}$ other examples include stabilization of the molecular layers via hydrogen bonding, ${ }^{[19]}$ and a few experiments report on the use of polar groups to enhance adsorption onto ionic substrates. ${ }^{[17,29,30]}$ However, there is no single set of design criteria for the morphology and stability of such films that can satisfy a wide range of possible applications. For example, molecular electronics applications may require that the molecules selfassemble in large, highly ordered, and defect-free domains. In 
contrast, self-healing and the ability to smooth asperities are more important for lubricants, while catalysts should provide accessible and effective reaction sites.

The long-term aim of our work is to design molecules that can form stable functional supramolecular structures on bulk insulators at room temperature. To achieve that, the chosen substrate and molecule should have the right balance of $\mathrm{M}-\mathrm{M}$ and $\mathrm{M}-\mathrm{S}$ interactions in order to inhibit dewetting and impose a regular molecular structure. In order to characterize the produced monolayers (MLs) with molecular resolution we employ noncontact atomic force microscopy (NCAFM) as this provides a nondestructive method to study the delicate structure of molecular layers, which has been successfully applied in the past to image individual molecules, aggregates, and films on insulating surfaces. ${ }^{[17,31-42]}$ However, while a number of supramolecular structures have been observed, ${ }^{[35-37,39,40]}$ the mechanisms of structure formation are not fully understood. Moreover, studies demonstrating high levels of control over the structure formation on insulators are still rare due to the subtle balance of $\mathrm{M}-\mathrm{M}$ and $\mathrm{M}-\mathrm{S}$ interactions.

In this study, we designed, synthesized and deposited organic molecules with interchangeable polar functional groups, a variable length aromatic body, and flexible hydrocarbon chains. The ability to modify each portion of these modular molecules allows us to study the competing interactions within these systems and improve our understanding of structure-property relationships. Sodium chloride $(\mathrm{NaCl})$, potassium chloride $(\mathrm{KCl})$, and rubidium chloride $(\mathrm{RbCl})$ were chosen as ionic substrates to provide different lattice constants as an additional control parameter. The deposited structures were imaged using NCAFM at room temperature and modeled using density functional theory (DFT). Our theoretical studies allowed us to describe the $\mathrm{M}-\mathrm{M}$ and $\mathrm{M}-\mathrm{S}$ interactions, and elucidate the structure and thermodynamic stability of the grown films. The results show that using the designed molecules we are able to form large-scale, highly ordered, 2D, porous molecular domains, which are stable at room temperature, and to control the size of the 2D pores. We can also form line structures or droplets (through molecular dewetting) by altering the molecule or changing the substrate lattice constant and, consequently, the $\mathrm{M}-\mathrm{M}$ and $\mathrm{M}-\mathrm{S}$ interactions.

\section{Results}

\subsection{CDB: Designing a Modular Molecule (or Building Block)}

The main objective of this work is to grow large-scale supramolecular frameworks on insulators via molecular deposition. To provide specific $\mathrm{M}-\mathrm{M}$ and $\mathrm{M}-\mathrm{S}$ interactions, 1,4-bis(cyanophenyl)-2,5-bis(decyloxy)benzene (CDB) molecules, based on a triphenyl core ended by two cyano substituents and substituted by two lateral decyloxy chains (see Figure 1A), have been designed.

Lateral decyloxy chains have been observed to promote supramolecular self-assembly by van der Waals (vdW) interactions between parallel aligned chains (interdigitation). ${ }^{[43]}$ A triphenyl core contributes to $\mathrm{M}-\mathrm{M}$ interactions through $\pi$-stacking. ${ }^{[4]}$ If only the interdigitation and $\pi$-stacking $\mathrm{M}-\mathrm{M}$ interactions were present, then 2D line structures would probably be formed. The added cyano groups, which are believed to be involved in hydrogen bonding to enhance $\mathrm{M}-\mathrm{M}$ interactions, ${ }^{[45]}$ also provide site-specific $\mathrm{M}-\mathrm{S}$ interactions, ${ }^{[17]}$ allowing other types of film structure to be stabilized.

In order to investigate the role of cyano groups in the balance of $\mathrm{M}-\mathrm{M}$ and $\mathrm{M}-\mathrm{S}$ interactions, the two cyano groups have been substituted by vinyl (1,4-bis(vinylphenyl)-2,5-bis(decyloxy)benzene) groups or methyl (1,4-bis(tolyl)-2,5-bis(decyloxy)benzene) groups. The role of $\pi$-stacking has been highlighted by elongating the aromatic core from three to five rings to form the 1,4-bis(4"-cyano-biphenyl)-2,5-bis(decyloxy)benzene (CBDB) molecule.

\section{2. $\mathrm{CDB}$ on $\mathrm{KCl}(001)$ : Self-Assembled Highly Ordered Porous Domains}

Targeting potential nanoelectronics applications, we would like to achieve the controlled formation of large, defect-free 2D

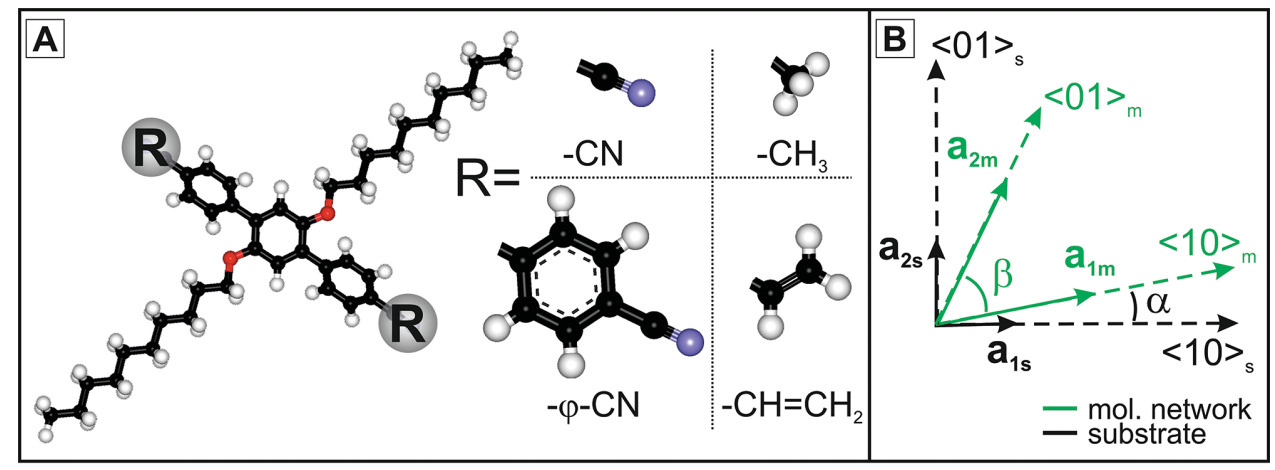

Figure 1. A) Ball and stick model of the molecule with interchangeable functional groups: $\mathrm{O}$ atoms are shown in red, $\mathrm{N}$ atoms in blue, $\mathrm{H}$ atoms in white, and $\mathrm{C}$ atoms in black. Molecules with the four different $\mathrm{R}$ end groups were synthesized, namely: 1,4-bis (4'-cyanophenyl)-2,5-bis (decyloxy) benzene (CDB) with the most polar cyano group - $\mathrm{CN}$; the less polar $-\mathrm{CH}=\mathrm{CH}_{2}$ vinyl group and the nonpolar methyl group $\mathrm{CH}_{3} ; 1,4-\mathrm{di}$ - (4"-cyanobiphenyl)2,5-(didecyleoxy) benzene molecule (CBDB has a larger aromatic body by adding a $-\varphi-C N$ group. B) Notation conventions for the epitaxy between the molecular network and the substrate. 


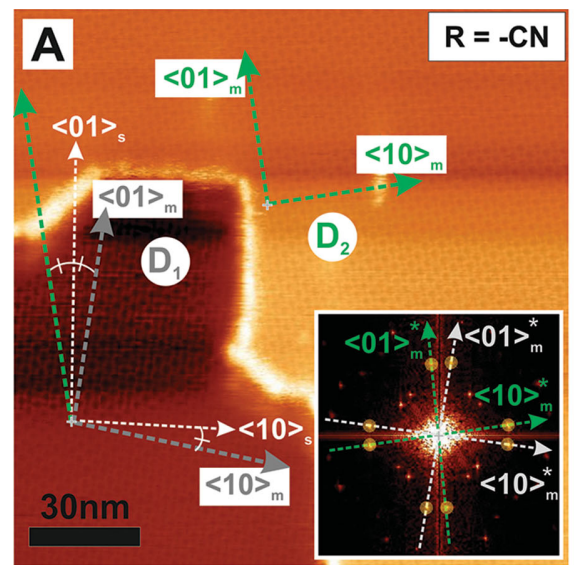

$\Delta \mathrm{Z}(\AA) 0$ 6.3

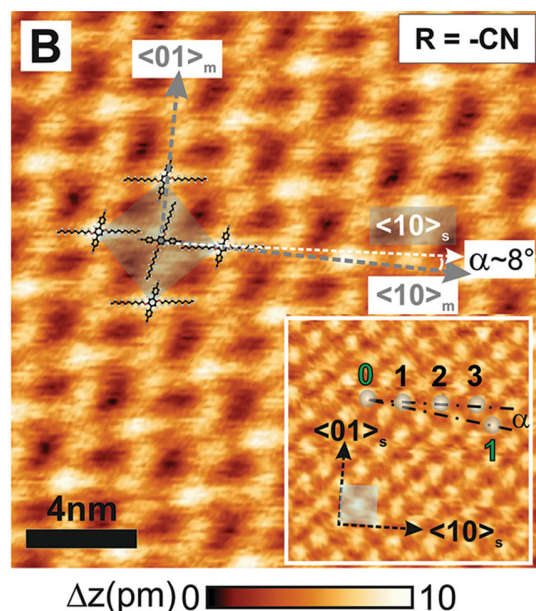

$\Delta \mathrm{z}(\mathrm{pm}) 0$

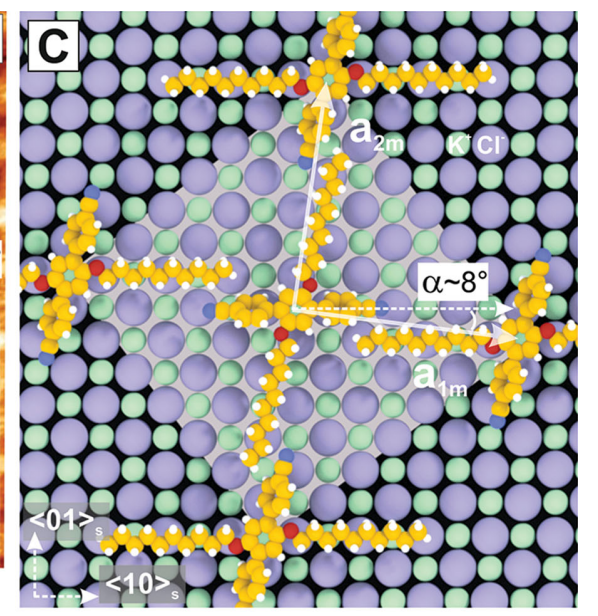

Figure 2. $\mathrm{CDB}$ molecules on $\mathrm{KCl}(001)$, A) NCAFM large-scale topography image (frame edge $=150 \mathrm{~nm} ; \gamma=-0.04 \mathrm{nN} \vee \mathrm{nm}, \mathrm{A}_{0}=10 \mathrm{~nm}$ ) showing two different molecular domains $\left(D_{1}, D_{2}\right)$ separated by a monatomic step of the substrate. Their $\langle 10\rangle_{m}$ axes, as derived from the FFT (inset), are $\pm(8 \pm 3)^{\circ}$ oriented with respect to the $\mathrm{KCl}\langle 10\rangle_{s}$ crystal orientation. B) Molecular-scale image (frame edge $=20 \mathrm{~nm} ; \gamma=-0.16 \mathrm{nN} V_{\mathrm{nm}}, \mathrm{A}_{0}=10 \mathrm{~nm}$ ) with structural model and orientation of the substrate with ionic resolution acquired on different areas of the substrate (inset: frame edge $=4 \mathrm{~nm}$ ). The unit cell parameters and its actual orientation with respect to the substrate are: $a_{1 \mathrm{~m}}=a_{2 \mathrm{~m}}=(2.18 \pm 0.06) \mathrm{nm}, \beta=90^{\circ}$ and $\alpha=(-8 \pm 3)^{\circ}$. (C) Proposed structural model: $a_{1 \mathrm{~m}}=a_{2 \mathrm{~m}}=2.23 \mathrm{~nm}, \beta=90^{\circ}$ and $\alpha=$ atan $(-0.5 / 3.5)=-8.1^{\circ}$. The experimental values confirm a point-on-point epitaxy of a square porous network.

layers, with molecules preferentially adsorbed on identical substrate sites in order to preserve the molecules' electronic and optical properties. The control parameters for supramolecular structures are the size of the central aromatic part of the molecule, the choice of its end groups, as well as the lattice constant of the substrate surface. The most striking structure observed in this work is an extended 2D porous network obtained by depositing one $\mathrm{ML}$ of $\mathrm{CDB}$ molecules on $\mathrm{KCl}(001)$ shown in Figure 2A.

In the course of deposition, the molecules initially decorate substrate step edges and then form large $\left(>300 \times 300 \mathrm{~nm}^{2}\right)$, homogeneous domains. Areas with different molecular domain orientations are mostly observed at step edges, as shown in Figure 2A. We note that NCAFM imaging of weakly bound molecules on insulating substrates at room temperature is very challenging as it must be performed with extremely weak tipsample interactions (note that the vertical contrast in Figure 2B is only $10 \mathrm{pm}$ ) in order to avoid manipulation of the molecules. A careful evaluation of the substrate orientation (see inset of Figure 2B) and the molecular layer in Figure 2B reveals a highly ordered square network in a point-on-point epitaxy with the substrate. Large defect-free domains $\left(>10^{4}\right.$ molecules) are observed on most areas of the surface. Following the notation conventions given in Figure $1 \mathrm{~B}$, the measured lattice constant of the molecular film is $a_{1 \mathrm{~m}}=a_{2 \mathrm{~m}}=(2.18 \pm 0.06) \mathrm{nm}$ and $\beta=$ $90^{\circ}$, which is within less than the $3 \%$ of the experimental error to the square point-on-point epitaxial matrix with the substrate of ${ }^{[46]}$ :

$\left(\begin{array}{l}\mathrm{a}_{1 m} \\ \mathrm{a}_{2 m}\end{array}\right)=M\left(\begin{array}{l}\mathrm{a}_{1 s} \\ \mathrm{a}_{2 s}\end{array}\right)$, with $M=\left(\begin{array}{cc}3.5 & -0.5 \\ 0.5 & 3.5\end{array}\right)$

yielding $a_{1 \mathrm{~m}}=a_{2 \mathrm{~m}}=2.23 \mathrm{~nm}$. Figure $2 \mathrm{C}$ shows a proposed model of this structure, where the molecules are kept in their gas-phase geometry (as calculated by DFT) and the hydrocarbon decyloxy chains are drawn straight. To further investigate the structure and stability of the observed porous structure we performed DFT calculations.

\subsection{Calculation of the Molecule-Surface Interactions}

In order to better understand the balance between the $\mathrm{M}-\mathrm{M}$ and $\mathrm{M}-\mathrm{S}$ interactions, we used (dispersion corrected) DFT according to the following plan. The adsorption of an individual CDB molecule on clean ionic surfaces was first investigated by carrying out geometry optimizations starting from different initial configurations. The molecule was then split into smaller molecular fragments, which were used to study the individual $\mathrm{M}-\mathrm{M}$ and $\mathrm{M}-\mathrm{S}$ interactions in the system. Using the results from these DFT simulations, we then benchmarked and employed a mixed quantum mechanics and molecular mechanics $(\mathrm{QM} / \mathrm{MM})^{[47,48]}$ embedding scheme. This allowed us to reduce the number of quantum atoms in our simulations and thus increase the surface area and compute the adsorption energies of various ML structures. To compare the obtained structures with the experimental NCAFM images we simulated theoretical images using a virtual AFM (vAFM).

To characterize the $\mathrm{M}-\mathrm{S}$ interaction on $\mathrm{KCl}(100)$ we performed Mulliken population analysis, produced charge density difference plots of the optimized adsorption geometry of a single CDB molecule, and studied the projected electronic density of states of the system. The highest occupied molecular orbital (HOMO) of the molecule lies nearly $2 \mathrm{eV}$ above that of the surface while the lowest unoccupied molecular orbital (LUMO) of the molecule lies nearly $2 \mathrm{eV}$ below that of the surface, effectively decoupling their electronic properties. These results demonstrated no significant charge transfer between the 


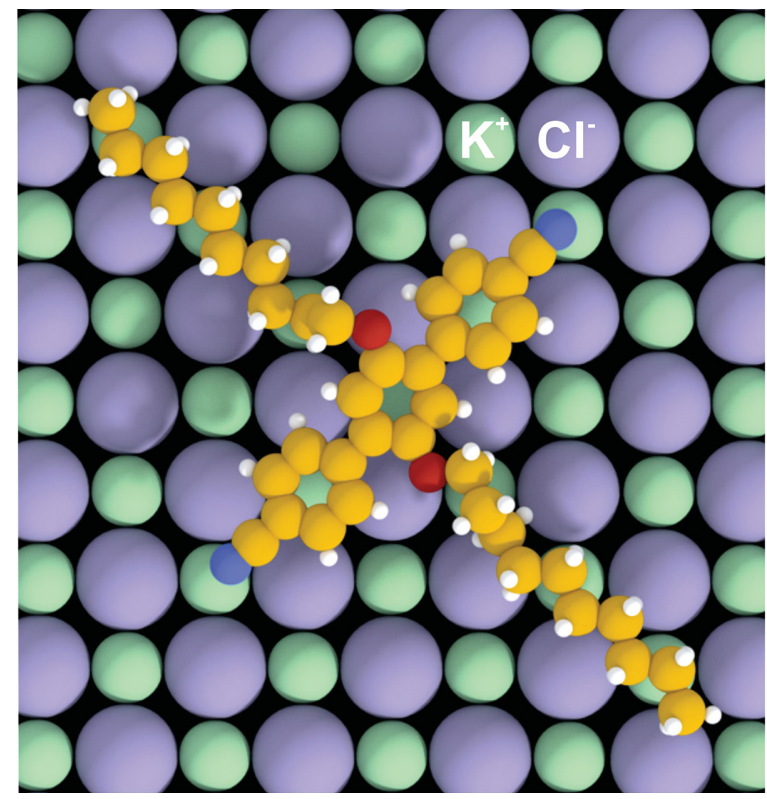

Figure 3. Configuration adsorption of a single $\mathrm{CDB}$ molecule on $\mathrm{KCl}(001)$ calculated in DFT. $\mathrm{K}$ cations are drawn in light green, $\mathrm{Cl}$ anions in purple. The total adsorption energy is $3.1 \mathrm{eV}$ and the adsorption configuration mainly results from the interaction between the cyano end groups and the $\mathrm{K}$ cations of the surface.

molecule and the $\mathrm{KCl}$ surface, indicating that the molecule is mainly physisorbed and that the electronic structure of the molecule is largely preserved. The adsorption energy can be partitioned into several contributions. The electronic interaction of the polar (oxygen, cyano) groups are about $0.7 \mathrm{eV}$, as calculated by a standard generalized gradient approximation (GGA) DFT functional. Meanwhile, vdW interactions contribute $2.4 \mathrm{eV}$ to the total adsorption energy of $3.1 \mathrm{eV}$. The adsorption configuration of the molecule is determined mainly by the interaction between the cyano groups (separated by $1.65 \mathrm{~nm}$ from each other, as shown in Figure 1) and the K cations of the surface. This anchoring of the molecule translates into a preference in orientation along the (110) direction in the lowest energy configuration shown in Figure 3.

In addition to this lowest energy monomer adsorption geometry, the CDB molecule can be rotated around one end group in either direction in order to fit the other cyano end group above other surface cation sites without significant loss of adsorption energy. This is due to the fact that, although the distance between the cations slightly increases, the molecule is flexible enough to still efficiently anchor to the surface.

In order to further elucidate the different $\mathrm{M}-\mathrm{S}$ and $\mathrm{M}-\mathrm{M}$ contributions involved in the CDB adsorption, we carried out DFT calculations of molecular fragments (cyanophenyl, decyloxy chains) on alkali halide surfaces. The strongest $\mathrm{M}-\mathrm{S}$ interaction comes from the $\mathrm{CN}$ functional group of cyanophenyl adsorbing to cation sites on the $\mathrm{KCl}$ surface. The fragment $\mathrm{CN}$ group adsorbs above a cation site while the attached benzene ring adsorbs parallel to the surface plane with combined adsorption energy of $0.7 \mathrm{eV}$. These results are consistent with the previous calculations that give the interaction of a physisorbed benzene ring with the $\mathrm{KCl}(001)$ surface of $0.5 \mathrm{eV}^{[49]}$ and the interaction of a cyano group with $\mathrm{KBr}(001)$ of $0.2 \mathrm{eV} \cdot[17,29]$ The adsorption energy of the $\mathrm{CN}$ group increases above anion vacancies, divacancies, and at step edges and kinks where it can interact with more cations at once.

The second significant contribution is between the $\mathrm{O}$ atoms of the decyloxy chains and the surface. However, in the full, unfragmented molecule the central phenyl ring adsorbs in a tilted configuration to minimize steric interactions with adjacent rings. This means that only one $\mathrm{O}$ atom can interact with the surface at a time, resulting in a net interaction that is much weaker than the $\mathrm{CN}$ interactions with surface $\mathrm{K}$ ion sites.

Finally, the rumpling of ionic surfaces results in the cations being displaced inside, towards the bulk and the anions slightly elevated above the surface plane, in agreement with the prior calculations $^{[50]}$ and experiments. ${ }^{[51]}$ However, this does not appreciably affect the adsorption of hydrocarbon chains as the differences in energy between various chain configurations at the surface are within $0.02 \mathrm{eV}$. Therefore, at room temperature the hydrocarbon chains should be quite mobile in contrast to the more stable anchoring groups.

\subsection{Calculation of the Molecule-Molecule Interactions}

In addition to the $\mathrm{M}-\mathrm{S}$ interactions described above, another major contribution affecting the growth of CDB supramolecular structures on $\mathrm{KCl}(001)$ comes from the $\mathrm{M}-\mathrm{M}$ interactions. Since the electronic properties of the molecule do not change significantly as a result of adsorption to the $\mathrm{KCl}(100)$ surface, the $\mathrm{M}-\mathrm{M}$ interactions can be studied in the gas phase. As expected, CN functional groups repel each other. However, CN groups interact favorably with the hydrocarbon decyloxy chains of adjacent molecules; this latter interaction energy is $0.2 \mathrm{eV}$ at an optimal distance of $0.36 \mathrm{~nm}$ when the $\mathrm{CN}$ and $\mathrm{CH}_{3}$ groups are positioned end to end. This value is in agreement with prior studies of the $\mathrm{CN}$-alkyl chain interaction $(0.12 \mathrm{eV}$ with a distance of $0.45 \mathrm{~nm}) \cdot{ }^{[52]}$

The benzene rings that make up the core of the molecule can also attract each other in a side-by-side configuration on the surface with $0.1 \mathrm{eV}$ of interaction energy with an optimal distance of $0.28 \mathrm{~nm}$ between the centers of the rings. This is consistent with prior studies that also estimate that $\pi$-stacking of parallel-displaced benzene rings can contribute up to $0.1 \mathrm{eV}$ to $\mathrm{M}-\mathrm{M}$ interaction. ${ }^{[53-56]}$ Finally, depending on the distance between rows on the alkali halide surface, the hydrocarbon chains may either attract due to vdW forces or repel each other at close range. This interaction is also on the order of $0.1 \mathrm{eV}$ at the optimal distance of $0.5 \mathrm{~nm}$ on the $\mathrm{KCl}(100)$ surface. It falls off to zero as the chains move farther away, and quickly becomes repulsive at distances shorter than $0.4 \mathrm{~nm}$.

\subsection{Calculation of the CDB Monolayer Structure}

We are now in a position to propose more detailed atomistic models of the CDB ML. Using the periodicity of the film formed on $\mathrm{KCl}(001)$ from experimental data as a constraint, we constructed periodic MLs of $\mathrm{CDB}$ on $\mathrm{KCl}(001)$ by placing 


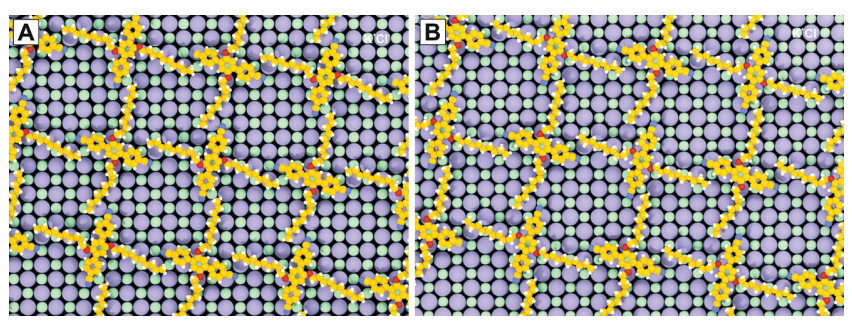

Figure 4. Atomistic representations of the ML structure of CDB molecules on $\mathrm{KCl}(001)$ as calculated by DFT. The depicted enantiopure configuration $(A)$ and the racemic configuration (B) are energetically degenerate.

molecules in various configurations on the surface and allowing the structures to relax. The lowest energy configurations are shown in Figure 4.

Since the CDB molecule is not symmetric, films can be either enantiopure (Figure 4A), racemic (Figure 4B), or somewhere in between. The two possible enantiopure as well as the racemic structures, however, were found to be energetically equivalent. In the ML configuration each CDB molecule gains $0.5 \mathrm{eV}$ via interactions with neighboring molecules. However, due to distortions from the ideal adsorption geometry, ML configurations shown in Figure 4 are only $0.3 \mathrm{eV}$ more stable per molecule than isolated $\mathrm{CDB}$ molecules on $\mathrm{KCl}(001)$, meaning that the total adsorption energy per molecule is increased to $3.4 \mathrm{eV}$.

To try and confirm the pore structure of the ML, and make direct link between theory and experiment, attempts were made to image the ML structure at large tip-surface distances to minimize the layer distortion by the tip. Although, generally this has not been possible due to a lack of signal, rarely images with measurable contrast were obtained (such as the one shown in Figure $5 \mathrm{C}$ ). To simulate an NCAFM image of the theoretical structure using a vAFM, we assumed that at long tip-substrate distance the tip can be well represented by a point dipole corresponding to a silanol group or $\mathrm{KCl}$ cluster at the end of the tip (see Methods for further discussion).
A theoretical image of the most stable atomistic structure of the $\mathrm{CDB} \mathrm{ML}$ on $\mathrm{KCl}(001)$ (shown in Figure $5 \mathrm{~A}$ ) calculated using a $\mathrm{VAFM},{ }^{[57]}$ a point-dipole tip model of 10 Debye, ${ }^{[58]}$ and a tip-substrate distance of $0.8 \mathrm{~nm}$ is shown in Figure 5B.

The bright lines in the image correspond to the main body of the CDB molecule and the two CN functional groups. The hydrocarbon chains are not visible due to a lack of electrostatic interactions with the tip. This theoretical image can be directly compared with the experimental image of $\mathrm{CDB}$ on $\mathrm{KCl}(001)$ shown in Figure 5C obtained at large tip-surface separation. Note that for both structures presented in Figure 4 there are alternating pores with the CN-groups or the hydrocarbon chains looking inwards, which can be seen in both experimental and theoretical images as squares with different contrast-the four marked molecules in Figures 5A, and B surround a pore with $\mathrm{CN}$-groups facing inwards. The qualitative agreement between theory and experiment suggests that the image interpretation is realistic and strengthens the suggestion that the pores are indeed empty.

\subsection{Modifying the Molecule}

To demonstrate control over the growth and structure of molecular films, we modified the CDB molecule in two ways. The first was to enlarge the central aromatic body of the molecule (see Figure $1 \mathrm{~A}$ with $R=\phi-\mathrm{CN}$ ). The idea was to confirm that this larger CBDB molecule is also able to form square porous networks and elucidate the effect that changing the size of the central body has on the network structure. Indeed, the geometrical conditions for forming a square porous network were again satisfied on $\mathrm{KCl}(001)$, as shown in Figure $\mathbf{6}$.

This modified molecule also forms large, defect-free domains in the shape of a 2D porous network. These domains are oriented differently with respect to the surface due to changes in commensurability and are composed of larger pores (pore size $4.8 \mathrm{~nm}^{2}$ for CDB and $6.1 \mathrm{~nm}^{2}$ for CBDB). The measured lattice constant of the CBDB molecular film is $a_{1 \mathrm{~m}}=a_{2 \mathrm{~m}}=$
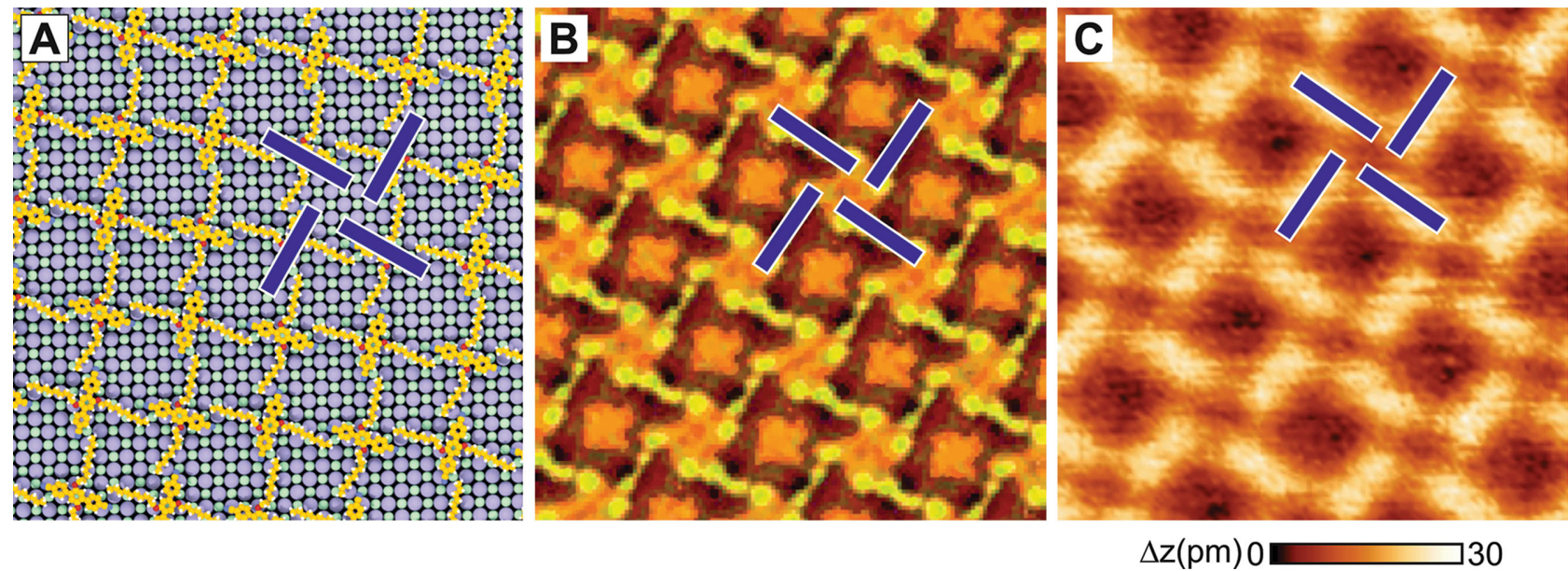

Figure 5. A) Atomistic representation (see Figure $4 A$ ) of a $M L$ of $C D B$ molecules on $\mathrm{KCl}(001)$. B) vAFM image of the $M L$ imaged using a 10 Debye point dipole for the tip and a tip-sample distance of $0.8 \mathrm{~nm}$. C) NCAFM topography image of CDB molecules on $\mathrm{KCl}(001)$ at room temperature (frame edge $=12 \mathrm{~nm}$ ). Experimental and vAFM parameters: $\gamma=-0.04 \mathrm{nN} \sqrt{ } \mathrm{nm}, \mathrm{A}_{0}=10 \mathrm{~nm}$. 


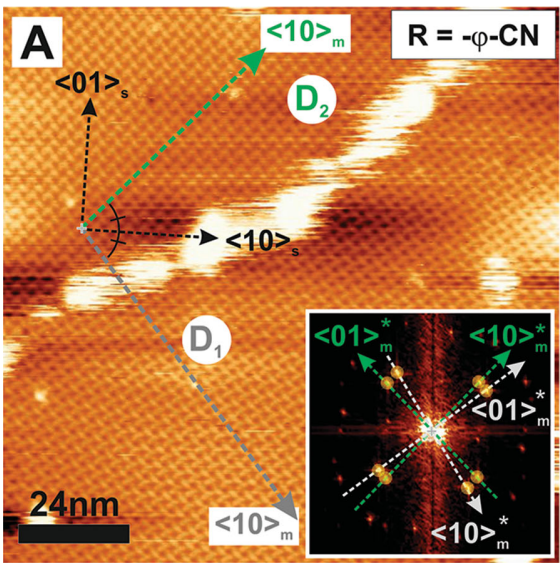

$\Delta z(\AA) 0$

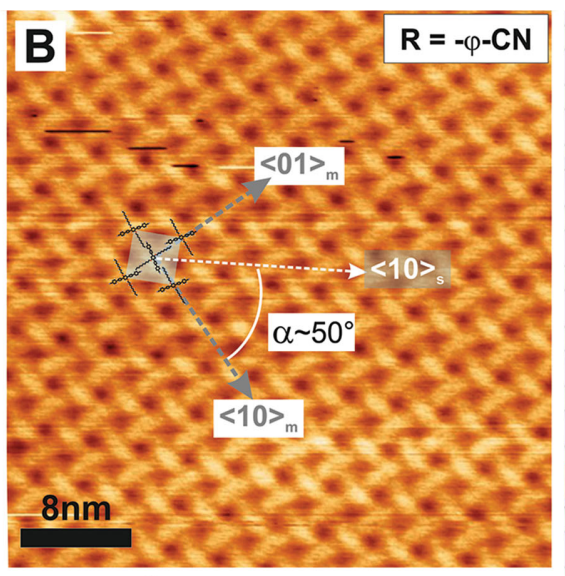

$\Delta \mathrm{z}(\AA)$

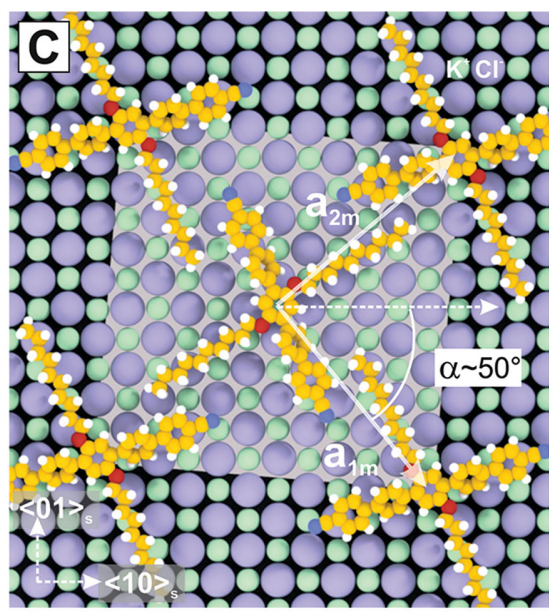

Figure 6. $\mathrm{CBDB}$ molecules on $\mathrm{KCl}(001)$. A) NCAFM large-scale topography image (frame edge $=120 \mathrm{~nm} ; \gamma=-0.03 \mathrm{nN} \vee \mathrm{nm}, \mathrm{A}_{0}=10 \mathrm{~nm}$ ) showing two differently oriented molecular domains $D_{1}$ and $D_{2}$. The inset shows the FFT analysis which reveals the orientation of the two domains. B) Molecular scale image (frame edge $=40 \mathrm{~nm}$, digital zoom of (A) showing the square porous molecular network as well as the orientation of the molecular lattice with respect to the substrate orientation: $a_{1 \mathrm{~m}}=a_{2 \mathrm{~m}}=(2.47 \pm 0.06) \mathrm{nm}, \beta=90^{\circ}$, and $\alpha=(-50 \pm 4)^{\circ}$. C) Proposed structural model taking into account that all $\mathrm{CN}$ groups adsorb above the $\mathrm{K}$ ions: $a_{1 \mathrm{~m}}=a_{2 \mathrm{~m}}=2.46 \mathrm{~nm}, \beta=90^{\circ}$, and $\alpha=\operatorname{atan}(-3 / 2.5)=-50.2^{\circ}$.

$(2.47 \pm 0.06) \mathrm{nm}$ and $\beta=90^{\circ}$. The closest epitaxial relation with the substrate is the one with an epitaxial matrix of:

$M=\left(\begin{array}{cc}2.5 & -3 \\ 3 & 2.5\end{array}\right)$

giving $a_{1 \mathrm{~m}}=a_{2 \mathrm{~m}}=2.46 \mathrm{~nm}$, as shown in Figure $6 \mathrm{C}$. The model proposed in Figure $6 \mathrm{C}$ is drawn with the molecules being rigid and their hydrocarbon chains straight. Differently to the monolayer structure of CDB where all molecules adsorb in identical orientations with respect to the two substrate surface directions, here every second molecule seems to be adsorbed slightly differently in order to fit the $\mathrm{CN}$ groups above the surface $\mathrm{K}$ ions. The formation of these porous layers can only be explained by $\mathrm{M}-\mathrm{M}$ interactions with a large contribution from the interaction between $\mathrm{CN}$ and $\mathrm{CH}_{3}$ groups.

To further demonstrate how the molecular design can affect the ML structure, we replace the polar cyano groups with less polar vinyl groups and nonpolar methyl groups. By doing so, we weaken one of the dominant interactions- the M-S interaction between anchoring end groups and cations on the ionic substrate-and hence affect the balance of interactions within the system. Lateral $\mathrm{M}-\mathrm{M}$ interactions between aromatic rings and hydrocarbon chains are then able to drive the system towards more closely packed structures.

For a weakened anchoring group, such as the vinyl-terminated aromatic core, a 2D organic layer is still formed on the $\mathrm{KCl}$ substrate, but the island borders appear very unstable (Figure 7A). Although the molecule was only slightly modified, the network formed is no longer a porous square one, as shown for CDB and $\mathrm{CBDB}$, but a 2D line structure, as shown in Figure 7B. The observed lattice parameters are $a_{1 \mathrm{~m}}=(2.5 \pm 0.3) \mathrm{nm}$, $a_{2 \mathrm{~m}}=(1.0 \pm 0.1) \mathrm{nm}$ and $\beta=90^{\circ}, a_{2 \mathrm{~m}}$ being the distance between neighboring molecular centers within each molecular line (Figure 7C). Compared with the overall length of the aromatic body of $1.65 \mathrm{~nm}$, this distance permits an overlap of the vinyl-phenyl terminal rings between molecules in adjacent lines, shown in the proposed model in Figure 7C, which is suitable for $\pi$-stacking.

When the aromatic core of the molecule is terminated by a nonpolar methyl group, there is no longer ML formation but a dewetting of the molecules into large crystallites occurs. Only the $\mathrm{KCl}$ step edges remain decorated by molecules (Figure 7D). The corresponding dissipation image in Figure 7E and the profile in Figure 7F show the height of the molecular crystal and confirms that it is not just a large bundle of $\mathrm{KCl}$ step edges but a different phase. These molecular crystals have a very mobile surface at room temperature and we were unable to achieve molecular resolution on top of them.

\subsection{Modifying the Surface}

The chosen ionic substrate most strongly influences the assembly of the molecules with an aromatic body functionalized by cyano groups (see Figure $1 \mathrm{~A}$ : CDB, $R=-\mathrm{CN}$ and CBDB, $R$ $=-\phi-\mathrm{CN})$. For this group of molecules, the vertical M-S interaction dominates the film formation, and in all structures the molecules adsorb with their cyano groups above cations of the substrate. The formation of different molecular organizations is governed by the delicate balance of the $\mathrm{M}-\mathrm{M}$ interactions. For the $\mathrm{KCl}$ substrate, where favorable $\mathrm{CN}-\mathrm{CH}_{3}$ interactions are possible while anchoring the molecules to their preferred adsorption site, the porous network is formed. For the other investigated substrates ( $\mathrm{NaCl}$ and $\mathrm{RbCl}$ ), it is $\pi$-stacking and for some systems possibly interdigitation of the hydrocarbon decyloxy chains that determines the formation of 2D line structures. The experimental data are reported in Figure 8.

For all these structures, the experimentally determined parameters show that there is an overlap of the aromatic cores of the assembled molecules that corresponds well to the distances normally observed for $\pi$-stacking. Interdigitation of the hydrocarbon chains is not always very significant and the interline distances vary. This is most probably due to the fact 


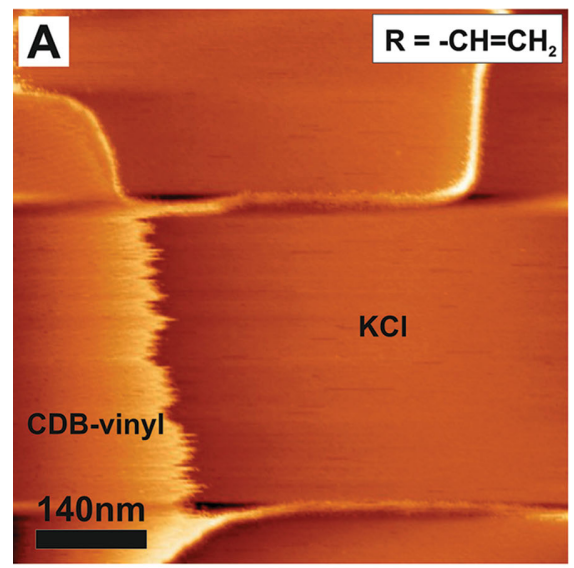

$\Delta \mathrm{z}(\mathrm{nm}) 0$

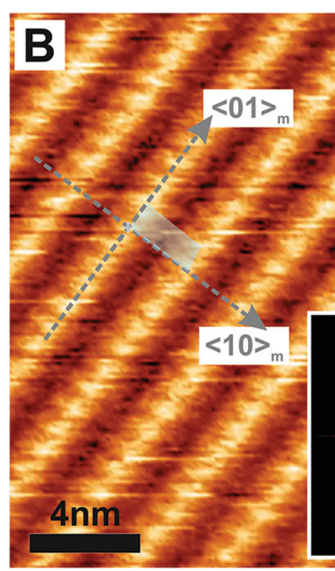

$\Delta \mathrm{z}(\AA) 0$

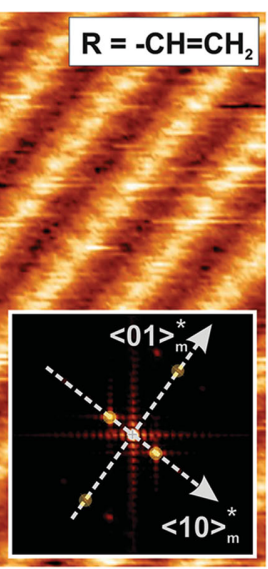

1.7

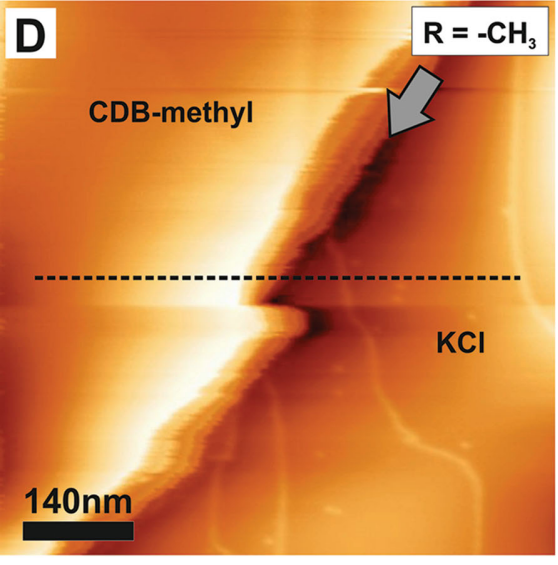

$\Delta \mathrm{z}(\mathrm{nm}) 0$

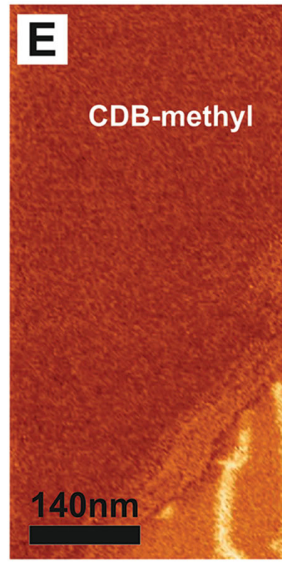

$\mathrm{E}_{\mathrm{d}}(\mathrm{eV} /$ cycle $) 0$
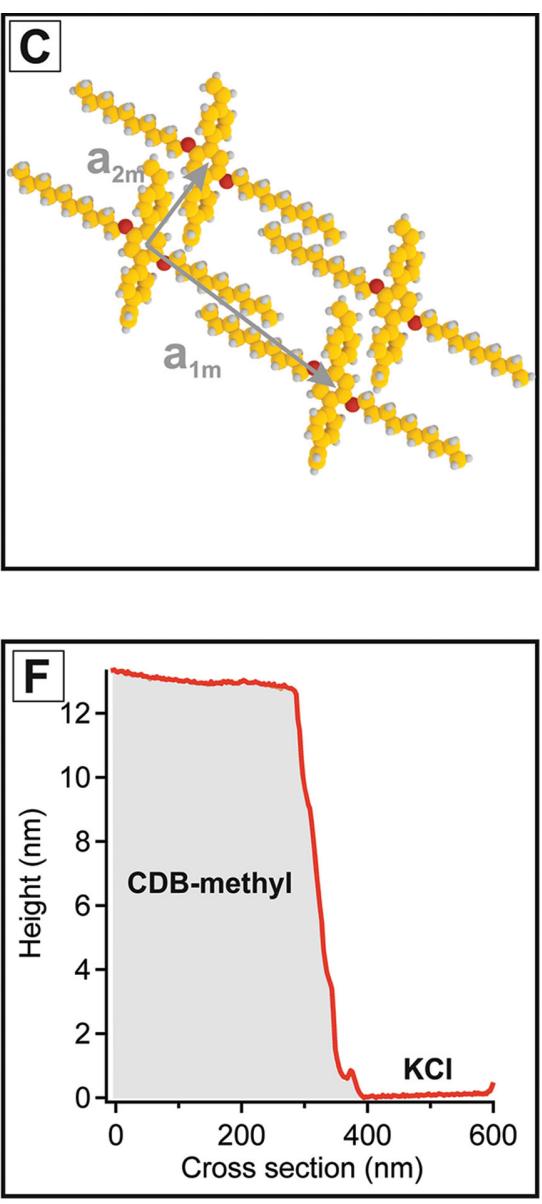

2.0

Figure 7. A) NCAFM topography image of vinyl-terminated CDB showing decorated $\mathrm{KCl}$ step edges and a molecular layer with instable island border due to diffusion of molecules on the surface (frame edge $=690 \mathrm{~nm} ; \gamma=-0.04 \mathrm{nN} \sqrt{\mathrm{nm}}, \mathrm{A}_{0}=10 \mathrm{~nm}$ ). B) Molecular scale image (frame edge $=20 \mathrm{~nm} ; \gamma=$ $\left.-0.11 \mathrm{nN} \sqrt{ } \mathrm{m}, \mathrm{A}_{0}=10 \mathrm{~nm}\right)$ showing the $2 \mathrm{D}$ line structure of the molecules with $a_{1 \mathrm{~m}}=(2.5 \pm 0.3) \mathrm{nm}, a_{2 \mathrm{~m}}=(1.0 \pm 0.1) \mathrm{nm}$ and $\beta=90^{\circ}$, as derived from the FFT (inset). C) Proposed structural model promoting $\pi$-stacking between phenyl cycles and interdigitation between decyloxy chains. D) NCAFM topography image of methyl-terminated CDB (frame edge $=690 \mathrm{~nm} ; \gamma=-0.04 \mathrm{nN} V_{\mathrm{nm}}, \mathrm{A}_{0}=10 \mathrm{~nm}$ ) on $\mathrm{KCl}(001)$. On the left side, there is an approximately $12 \mathrm{~nm}$ high molecular crystallite as can be seen from the profile shown in $\mathrm{F}$, as well as from the dissipation image (eV/cycle) shown in $\mathrm{E}$ which shows a clear contrast between the $\mathrm{KCl}$ surface and the molecular crystal. The dissipation signal is larger on the $\mathrm{KCl}$ step edges decorated by molecules.

that these chains are very mobile at room temperature and for the larger CBDB molecule in particular, there is a lot of room between individual $\pi$-stacked molecular rows. For the other functional end groups considered (i.e., vinyl and methyl termination), the main observation is that there are line structures for the vinyl groups on all investigated substrates and that there is a more or less rapid dewetting process for all methyl terminated molecules (data not shown).

\section{Discussion}

One of the major features governing assembly of 2D networks on insulating surfaces is the balance of relatively weak interactions that controls the supramolecular structure formation. Our experimental and theoretical results illustrate this fine balance at work. On the $\mathrm{KCl}(001)$ surface, $\mathrm{CDB}$ molecules form a defect free, porous $2 \mathrm{D}$ structure. In this system, the
$\mathrm{CN}$ to surface-cation interaction is the strongest site specific $\mathrm{M}-\mathrm{S}$ interaction component that plays a large role in the structure formation. As this interaction is weakened via a vinyl substitution of the $\mathrm{CN}$ group, the other contributions become more significant resulting in the preferential formation of a 2D line structure. Indeed, previous studies indicate that $\pi$-stacking should contribute significantly to $\mathrm{M}-\mathrm{M}$ interactions. ${ }^{[53-56]}$ Furthermore, weakening of the anchoring group's interaction with the surface results in reduction of adsorption strength and leads to dewetting. The molecules still adsorb to $\mathrm{KCl}(001)$ terraces and decorate step edges initially, as previously observed. However, as the $\mathrm{M}-\mathrm{M}$ interaction becomes stronger than the $\mathrm{M}-\mathrm{S}$ interaction, the formation of large domains of molecular crystals is favored over the formation of defect-free MLs.

Since our experimental data depict regular networks that are free of defects, it is reasonable to infer that room temperature NCAFM provides information on the average position 


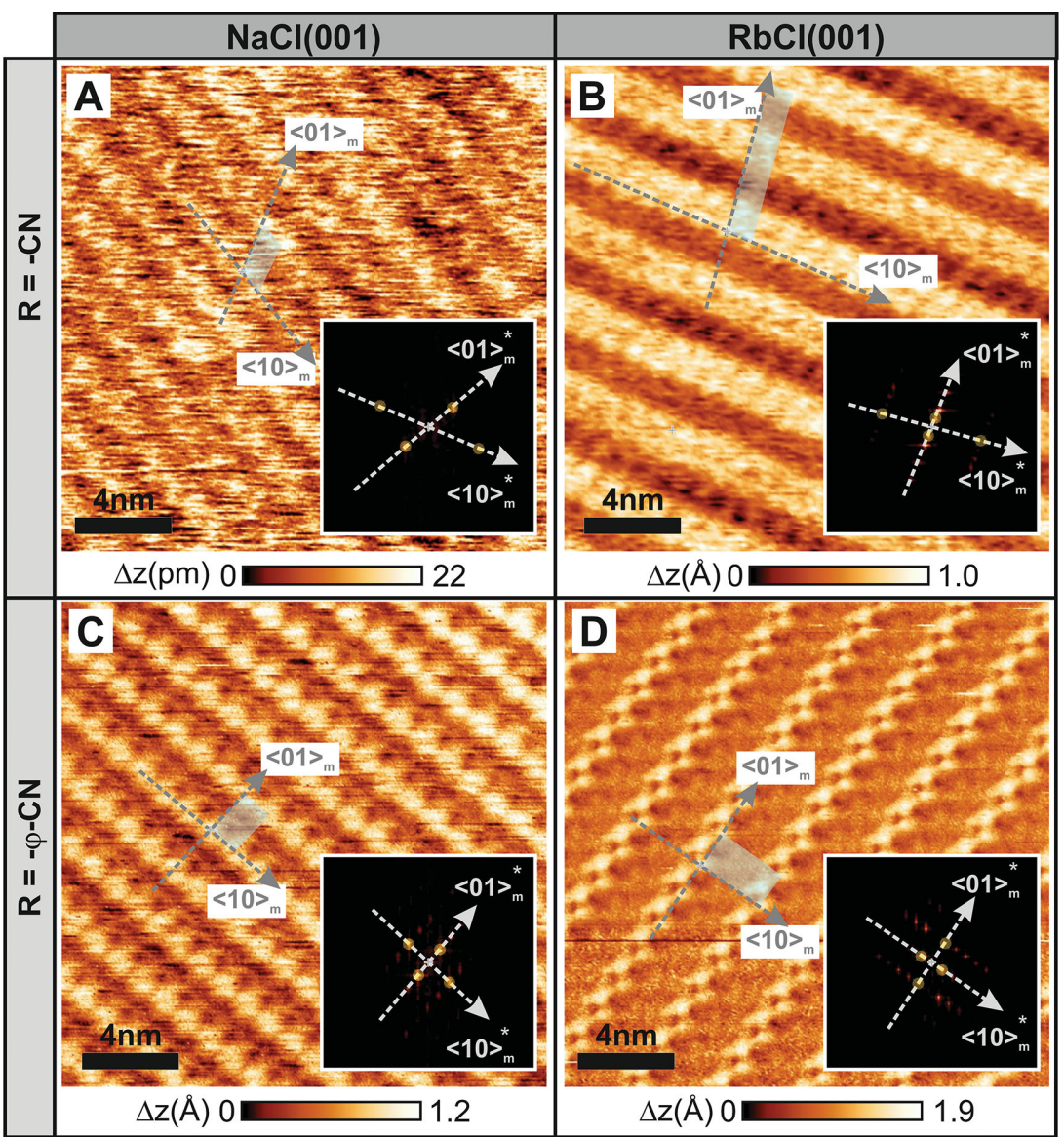

Figure 8. NCAFM topography images of $C D B(R=-C N)$ and $C B D B(R=-\phi-C N)$ on $\mathrm{NaCl}(001)$ and $\mathrm{RbCl}(001)$ including each an inset of the FFT used to determine the parameters of the molecular layer. Frames edges are all $20 \mathrm{~nm}$. A) CDB/NaCl: $a_{1 \mathrm{~m}}=1.16 \mathrm{~nm}, a_{2 \mathrm{~m}}=1.99 \mathrm{~nm}$, $\beta=120^{\circ} ; \gamma=-0.1 \mathrm{nN} \sqrt{\mathrm{nm}}, \mathrm{A}_{0}=10 \mathrm{~nm}$. B) CDB $/ \mathrm{RbCl}: a_{1 \mathrm{~m}}=1.04 \mathrm{~nm}, a_{2 \mathrm{~m}}=2.94 \mathrm{~nm}, \beta=95^{\circ} ; \gamma=$ $-0.25 \mathrm{nN} \sqrt{ } \mathrm{mm}, \mathrm{A}_{0}=10 \mathrm{~nm}$. C) $\mathrm{CBDB} / \mathrm{NaCl}: a_{1 \mathrm{~m}}=1.3 \mathrm{~nm}, a_{2 \mathrm{~m}}=2.2 \mathrm{~nm}, \beta=90^{\circ} ; \gamma=-0.12 \mathrm{nN} \sqrt{\mathrm{nm}}$, $\mathrm{A}_{0}=10 \mathrm{~nm}$. D) CBDB $/ \mathrm{RbCl}: a_{1 \mathrm{~m}}=1.5 \mathrm{~nm}, a_{2 \mathrm{~m}}=3.0 \mathrm{~nm}, \beta=90^{\circ} ; \gamma=-0.11 \mathrm{nN} \sqrt[\mathrm{nm}]{ }, \mathrm{A}_{0}=10 \mathrm{~nm}$. Experimental error bars for these data are estimated to be within $10 \%$.

rather than the instantaneous position of atoms on the surface. Mobile features, such as diffusing molecules, are typically not experimentally observable on the timescale of NCAFM image acquisition and must be stabilized before they can be observed. Averaging likely encompasses both full molecular motion and the motion of individual groups. For instance, the hydrocarbon chains of decyloxy groups can be stabilized by an interaction with the CN group of a neighboring molecule, however, in the proposed ML configuration the hydrocarbon chains are weakly bound and free to move away from neighboring $\mathrm{CN}$ groups by overcoming a $0.2 \mathrm{eV}$ barrier. Preliminary molecular dynamics simulations confirm that CDB molecules are experiencing significant dynamics. Furthermore, our experimental images illustrate that molecular island borders are commonly unstable (see for example Figure 7A) and that molecular islands are mainly stabilized by substrate surface step edges. Investigating these dynamic effects requires expanding the size and time scale of our simulations. We are currently developing a force field for this specific system and a general method for rapidly optimizing molecule-surface force fields for adsorbates on insulators.

\section{Conclusions}

In summary, we have successfully designed a group of molecules and achieved control over their assembly into highly ordered, defect-free, 2D molecular networks on ionic alkali halide surfaces. In order to avoid dewetting while still maintaining a high degree of ordering of the organic layer, polar anchoring groups were added to the molecule's core to strengthen the $\mathrm{M}-\mathrm{S}$ interaction. Flexible $\mathrm{M}-\mathrm{M}$ interactions were achieved via $\pi$-stacking of phenyl rings of the molecule's core, interdigitation of hydrocarbon chains, and via an interaction between the hydrocarbon chains with the cyanophenyl rings. The strength of the latter interaction was confirmed by DFT calculations. To control the assembly, we modified the number of phenyl rings in the central part of the molecule, its polar end groups, as well as the ionic substrate. These results demonstrate that the delicate balance between $\mathrm{M}-\mathrm{M}$ and $\mathrm{M}-\mathrm{S}$ interactions can be used to control not only the orientation and spacing of $\pi$-stacked and interdigitated lines (2D line growth), but more interestingly the growth of a porous $2 \mathrm{D}$ network with adjustable pore size. A detailed understanding of the film-formation mechanism was obtained by means of theoretical calculations, which revealed the strength of the competing $\mathrm{M}-\mathrm{M}$ and $\mathrm{M}-\mathrm{S}$ interactions and elucidated the experimentally found porous structure. The most striking result of our work is that we could obtain a defect-free porous network of more than $10^{4}$ molecules. Such porous networks are prospective candidates for optical and catalytic applications where either reactive clusters can be deposited inside the pores or functional groups added to the molecules. As all molecules within the network are adsorbed on identical substrate sites and the substrate is a bulk insulator, this guarantees that the molecule's properties are entirely preserved.

\section{Experimental Section}

Molecule Synthesis: The starting point of the molecular synthesis was the CDB molecule, which consists of a central part with three phenyl rings, the outer ones being terminated by polar cyano end groups (Figure 1A). Two decyloxy chains were attached to the central ring. In order to control on the self-assembly of the molecule we chose to vary two parameters in the molecular design: first, the polar cyano groups were substituted by the less polar vinyl or the nonpolar methyl groups; second, the length of the central part was increased to five rings, the outer ones in each case being terminated by the cyano end groups (see Figure 9).

1,4-dibromo-2,5-bis(decyloxy)benzene (1.0g, $1.8 \mathrm{mmol}$ ) and 4-substitutedphenylboronic acid $(1.2 \mathrm{mmol}$ ) were dissolved in $40 \mathrm{~mL}$ of DMF (see Figure 9). Then, an aqueous solution of $\mathrm{K}_{2} \mathrm{CO}_{3}(0.5 \mathrm{M}, 6 \mathrm{~mL})$ and $\mathrm{Pd}\left(\mathrm{PPh}_{3}\right)_{4}$ catalyst $(42 \mathrm{mg}, 0.03 \mathrm{mmol}$ ) were added. The resulting mixture was heated at $150{ }^{\circ} \mathrm{C}$ for $48 \mathrm{~h}$. Then, the solvent was removed 


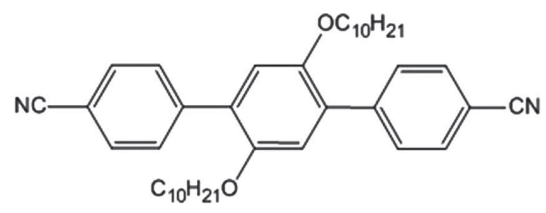

1,4-bis(cyanophenyl)-2,5-bis(decyloxy)benzene

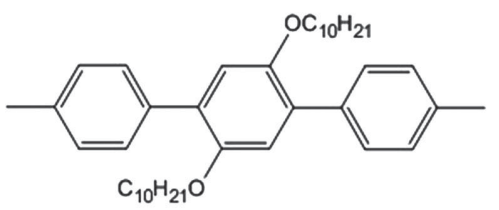

1,4-bis(tolyl)-2,5-bis(decyloxy)benzene

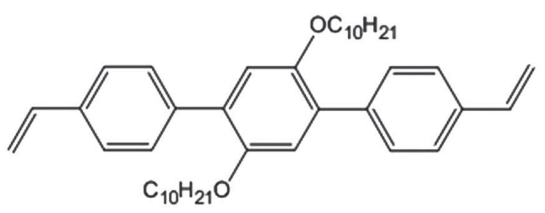

1,4-bis(4'-vinyl)-2,5-bis(decyloxy)benzene

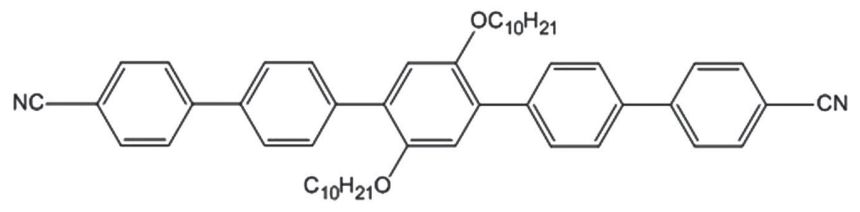

1,4-bis(4"-cyanobiphenyl)-2,5-bis(decyloxy)benzene

Figure 9. Chemical sketchs of tailored molecules.

under reduced pressure. The crude solid was dissolved in $100 \mathrm{~mL}$ of Chloroform. The organic solution was washed three times with $100 \mathrm{~mL}$ of water. The solvent was removed under reduced pressure. The resulting white solid is purified by column chromatography (silica gel, acetone/petroleum ether 1:1). The solid was recrystallized in acetonitrile to give a pure white solid $(710 \mathrm{mg}, 67 \%)$.

Noncontact Atomic Force Microscopy: NCAFM images were acquired at room temperature by a commercial AFM (VT-AFM, Omicron Nanotechnology GmbH 65232 Taunusstein, Germany) equipped with homebuilt electronics and an RHK controller (SPM 1000, PLL Pro II, RHK Technology Inc. Troy, MI 48083 USA). Cantilevers used are nanosensors (PPP-NCL, resonance frequency $f_{0}=150 \mathrm{kHz}$, spring constant $\mathrm{k}=30$ $\mathrm{N} \mathrm{m}^{-1}$, quality factor $Q$ approximately 40000 ) operated at oscillation amplitudes $A_{0}$ of $10 \mathrm{~nm}$.

Sample Preparation: The single crystal ionic substrates $\mathrm{NaCl}, \mathrm{KCl}$, and $\mathrm{RbCl}$ (MaTecK $\mathrm{GmbH}, 52428$ Jülich, Germany) were cleaved ex situ, quickly introduced into UHV and annealed to approximately $200{ }^{\circ} \mathrm{C}$ for $\mathrm{l} \mathrm{h}$ in order to obtain atomically clean substrates with large terraces. Molecules were deposited by evaporation from homebuilt crucibles

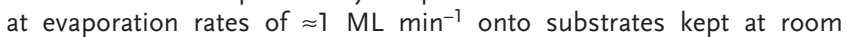
temperature.

Experimental Image Processing and Evaluation: Experimental NCAFM images were analyzed by using the WsXM software. ${ }^{[59]}$ All quantitative parameters given in the text (distances, angles) result from a combined analysis of the experimental images in real (topography, frequency shift $(\Delta f)$, self-correlation of them) and reciprocal space (FFT). For that purpose, a careful drift-correction of all images was performed by calculating the drift vector from a series of subsequent up- and downscans and then applying the drift correction procedure provided by the WsXM software. All distances and directions were calibrated with respect to the ionic crystal surface from atomically resolved images of the substrate. The experimental parameters for the oscillating conditions of the cantilever are given in the form of the so-called normalized frequency shift $\gamma$ introduced by Giessib|[60] with $\gamma=\Delta f \times \mathrm{k} \times \mathrm{A}_{0}^{3 / 2} / f_{0}$, and the energy dissipation $\mathrm{E}_{0}=\pi \times \mathrm{k} \times \mathrm{A}_{0}{ }^{2} / Q$ in [eV/cycle]. ${ }^{[61]}$

Density Functional Theory: DFT simulations to examine the interactions responsible for $\mathrm{CDB}$ adsorption and compare competing interactions between molecules on the surface were performed with the CP2K code using the PBE GGA density functional and a mixed Gaussian and plane waves basis set. ${ }^{[62,63]}$ These calculations included geometry minimizations of fragments of the CDB molecule interacting in the gas phase and fragments of the molecule interacting with the $\mathrm{KCl}(001)$, $\mathrm{NaCl}(001)$, and $\mathrm{RbCl}(001)$ surfaces. The surface was represented using four atomic layers with one fixed layer at the bottom and three layers of relaxed atoms in order to reproduce the band gap, rumpling, and lattice constants. We employed semiempirical long-range dispersion corrections ${ }^{[64]}$ in order to represent vdW interactions in the system. The MOLOPT ${ }^{[65]}$ basis set was used to minimize basis set superposition error.

The lowest energy configuration of each molecule was computed by placing the molecule onto each surface in various positions and optimizing the geometry. These starting positions were obtained by rotating the molecule by $2^{\circ}$ increments on the surface. The molecule was then divided into several main components by breaking bonds in order to examine the various contributions to adsorption energy. Each of these broken bonds was terminated with an $\mathrm{H}$ atom. The fragments studied include A) a hexane molecule representing the hydrocarbon chains, B) a benzonitrile molecule representing the functional groups of the larger $C D B$ molecule, and $C$ ) a benzene molecule representing the core of the CDB molecule.

Embedded Slab (QM/MM): A hybrid QM/MM method ${ }^{[47,48]}$ was used to increase the surface area in these simulations in order to study $\mathrm{ML}$ structures. The $\mathrm{KCl}$ surface was represented using one layer of quantum atoms and three layers of classical atoms. The QM region was treated in the same way as the DFT calculations described in the previous section. The MM region was represented using a set of classical parameters by Catlow et al. ${ }^{[66]}$ and the charges were smeared using Gaussian functions according to ionic radii. Using this treatment, the $\mathrm{KCl}(100)$ surface was calculated to have a band gap of $4.6 \mathrm{eV}$ and surface rumpling and lattice constants in good agreement with experiment. A more detailed description of this method will be published separately. ${ }^{[67]}$

Virtual Atomic Force Microscopy: Theoretical NCAFM images were produced using a point dipole model of the NCAFM tip. For experimental images taken at large tip-sample distances, it is reasonable to attribute the observed image contrast to electrostatic interactions between a dipole moment present in the tip itself and the potential of the sample. This method allows us to produce a force field directly from DFT calculations, as has been discussed previously ${ }^{[5]}$ and evaluated in the context of imaging small molecules on $\mathrm{NiO}(100)$. While the tips employed in this study are not metal coated tips as in the previous study, ${ }^{\left[{ }^{88]}\right.}$ they may still possess permanent dipole moments near the tip apex depending on tip termination. Si tips used in this work are likely to be terminated by inert silanol or bisilanol groups, ${ }^{[68]}$ which may result in a significant dipole moment at the tip apex. While the actual dipole moment of this tip termination is unknown, previous calculations suggest that the dipole moment of an isolated silanol group is of the order of $1.5 \mathrm{D} \cdot{ }^{[69]}$ Fragments from the $\mathrm{KCl}$ surface are also very plausible tip contaminants.

In this data set, we do not have long-range force curves or large sets of scanlines over the bare surface so were not able to explicitly fit the macroscopic vdW contributions or the magnitude of the dipole moment. ${ }^{[58]}$ The interactions between the macrotip and the sample were represented using a generic tip with a Hamaker constant of $5.94 \times 10^{-20} \mathrm{~J}$, a tip radius of $3.95 \mathrm{~nm}$, and a tip angle $\gamma$ of $16.42^{\circ}$. Since this contribution is macroscopic, it will have a large effect on the frequency shift observed and can provide useful information regarding the true tip-surface distance. In this work, however, we were only 
interested in the observable image contrast at $0.8-1.0 \mathrm{~nm}$ tip-surface distances where a generic representation of the macrotip should be sufficient. Simulations were performed using the same parameters as in experiment: $150 \mathrm{kHz}$ resonance frequency, a $30 \mathrm{~N} \mathrm{~m}^{-1}$ spring constant, and $10 \mathrm{~nm}$ oscillation amplitude using the vAFM code..$^{[57]}$ We simulated images using both negatively and positively oriented dipole moments of several magnitudes at several heights for comparison. A positively oriented 10 Debye tip scanning $0.8 \mathrm{~nm}$ above the surface provided the best agreement with the experimental images shown.

\section{Acknowledgements}

Financial support of this research by the Agence Nationale de la Recherche with the NANOKAN project (ANR-11-BS10-0004) is gratefully acknowledged. D.Z.G. was supported by Chevron Oronite LLC. M.W. is grateful to the Leverhulme Trust (grant F/07134/CK) for financial support. F.F.C. is supported by the MEXT WPI programme. The authors acknowledge the use of the HECTOR and the ARCHER high-performance computing facilities via our membership to the UK's HPC Materials Chemistry Consortium, which is funded by EPSRC (EP/F067496).

Received: September 11, 2014 Revised: October 20, 2014 Published online:

[1] F. Besenbacher, J. V. Lauritsen, S. Wendt, Nano Today 2007, 2, 30.

[2] G. Bhalla, M. H. Tsang, D. Gao, Q. Chen, W. Ruhe, N. Ushioda, SAE International 2012, 5, 496.

[3] A. M. Barnes, K. D. Bartle, V. R. A. Thibon, Tribol. Int. 2001, 34, 389.

[4] C. Joachim, J. K. Gimezewski, A. Aviram, Nature 2000, 408, 541.

[5] J. R. Heath, Rev. Mater. Res. 2009, 39, 1.

[6] H. Song, M. A. Reed, T. Lee, Adv. Mater. 2011, 23, 1583.

[7] T. Yokoyama, S. Yokoyama, T. Kamikado, Y. Okuno, S. Mashiko, Nature 2001, 413, 619.

[8] M. de Wild, S. Berner, H. Suzuki, H. Yanagi, D. Schlettwein, S. Ivan, A. Baratoff, H.-J. Güntherodt, T. A. Jung, ChemPhysChem 2002, 3, 825.

[9] C. Bobisch, Th. Wagner, A. Bannani, R. Möller, J. Chem. Phys. 2003, $119,9804$.

[10] L. Grill, M. Dyer, L. Lafferentz, M. Persson, M. V. Peters, S. Hecht, Nat. Nanotechnol. 2007, 2, 687.

[11] M. Abel, S. Clair, O. Ourdjini, M. Mossoyan, L. Port, J. Am. Chem. Soc. 2011, 133, 1203.

[12] O. Ourdjini, R. Pawlak, M. Abel, S. Clair, L. Chen, N. Bergeon, M. Sassi, V. Oison, J. M. Debierre, R. Coratger, L. Porte, Phys. Rev. B 2011, 84, 125421.

[13] P. Payamyar, K. Kaja, C. Ruiz-Vargas, A. Stemmer, D. J. Murray, C. J. Johnson, B. T. King, F. Schiffmann, J. VandeVondele, A. Renn, S. Götzinger, P. Ceroni, A. Schütz, L.-T. Lee, Z. Zheng, J. Sakamoto, A. D. Schlüter, Adv. Mater. 2014, 26, 2052.

[14] Z. Zheng, L. Opilik, F. Schiffmann, W. Liu, G. Bergamini, P. Ceroni, L.-T. Lee, A. Schütz, J. Sakamoto, R. Zenobi, J. VandeVondele, A. D. Schlüter, J. Am. Chem. Soc. 2014, 136, 6103.

[15] B. Baris, J. Jeannoutot, V. Luzet, F. Palmino, A. Rochefort, F. Chérioux, ACS Nano 2012, 6, 6905.

[16] R. Bennewitz, J. Phys.: Condens. Matter 2006, 18, R417.

[17] A. Hinault, A. Pujol, F. Chaumeton, D. Martrou, A. Gourdon, S. Gauthier, Beilstein J. Nanotechnol. 2012, 3, 221.

[18] C. M. Hauke, R. Bechstein, M. Kittelmann, C. Storz, A. F. M. Kilbinger, P. Rahe, A. Kühnle, ACS Nano 2013, 7, 5491.
[19] R. Pawlak, L. Nony, F. Bocquet, V. Oison, M. Sassi, J.-M. Debierre, C. Loppacher, L. Porte, J. Phys. Chem. C 2010, 114, 9290.

[20] P. Rahe, M. Nimmrich, A. Kühnle, Small 2012, 8, 2969.

[21] C. Loppacher, U. Zerweck, L. M. Eng, S. Gemming, G. Seifert, C. Olbrich, K. Morawetz, M. Schreiber, Nanotechnology 2006, 17, 1568.

[22] M. Kittelmann, M. Nimmrich, J. L. Neff, P. Rahe, W. Greń, X. Bouju, A. Gourdon, A. Kühnle, J. Phys. Chem. C 2013, 117, 23868.

[23] J. L. Neff, M. Kittelmann, R. Bechstein, A. Kühnle, Phys. Chem. Chem. Phys. 2014, 16, 15437.

[24] S. A. Burke, J. M. Topple, P. Grütter, J. Phys.: Condens. Matter 2009, 21, 423101.

[25] L. Nony, E. Gnecco, A. Baratoff, A. Alkauskas, R. Bennewitz, O. Pfeiffer, S. Maier, A. Wetzel, E. Meyer, Ch. Gerber, Nano Lett. 2004, 11, 2185.

[26] P. Rahe, M. Kittelmann, J. L. Neff, M. Nimmrich, M. Reichling, P. Maass, A. Kühnle, Adv. Mater. 2013, 25, 3948.

[27] U. Zerweck, C. Loppacher, L. M. Eng, Nanotechnology 2006, 17, S107.

[28] S. Maier, L.-A. Fendt, L. Zimmerli, T. Glatzel, O. Pfeiffer, F. Diederich, E. Meyer, Small 2008, 4, 1115.

[29] B. Such, T. Trevethan, T. Glatzel, S. Kawai, L. Zimmerli, E. Meyer, A. L. Shluger, C. H. M. Amijs, P. De Mendoza, A. M. Echavarren, ACS Nano 2010, 4, 3429.

[30] A. Hinaut, K. Lekhal, G. Aivazian, S. Bataillé, A. Gourdon, D. Martrou, S. Gauthier, J. Phys. Chem. C 2011, 115, 13338.

[31] T. Kunstmann, A. Schlarb, M. Fendrich, Th. Wagner, R. Möller, Phys. Rev. B 2005, 71, 121403.

[32] H. Onishi, A. Sasahara, H. Uetsuka, T. Ishibashi, Appl. Surf. Sci. 2002, 188, 265

[33] Y. Namai, K. Fukui, Y. Iwasawa, Nanotechnology 2004, 15, S49.

[34] L. Nony, R. Bennewitz, O. Pfeiffer, E. Gnecco, A. Baratoff, E. Meyer, T. Eguchi, A. Gourdon, C. Joachim, Nanotechnology 2004, 15, S91.

[35] S. A. Burke, J. M. Mativetsky, R. Hoffmann, P. Grutter, Phys. Rev. Lett. 2005, 94, 096102.

[36] T. Dienel, C. Loppacher, S. C. B. Mannfeld, R. Forker, T. Fritz, Adv. Mater. 2008, 20, 959.

[37] S. A. Burke, W. Ji, J. M. Mativetsky, J. Topple, S. Fostner, H. J. Gao, H. Guo, P. Grutter, Phys. Rev. Lett. 2008, 100, 7.

[38] J. Schutte, R. Bechstein, P. Rahe, A. Kuhnle, H. Langhals, Phys. Rev. B 2009, 79, 045428.

[39] F. Loske, R. Bechstein, J. Schutte, F. Ostendorf, M. Reichling, A. Kuhnle, Nanotechnology 2009, 20, 065606.

[40] M. Kittelmann, P. Rahe, A. Kuhnle, J. Phys. Condens. Matter 2012, 24, 354007.

[41] K. Lämmle, T. Trevethan, A. Schwarz, M. Watkins, A. Shluger, R. Wiesendanger, Nano. Lett. 2010, 10, 2965.

[42] A. Schwarz, D. Z. Gao, K. Lämmle, J. Grenz, M. Watkins, A. Shluger, R. Wiesendanger, J. Phys. Chem. C 2013, 117, 1105.

[43] J. A. A. W. Elemans, S. Lei, S. De Feyter, Angew. Chem., Int. Ed. 2009, 48, 7298 .

[44] Y. Makoudi, M. Beyer, J. Jeannoutot, F. Palmino, F. Picaud, F. Chérioux, Chem. Commun. 2014, 50, 5714.

[45] Y. Makoudi, F. Palmino, M. Arab, E. Duverger, F. Chérioux, J. Am. Chem. Soc. 2008, 130, 6670.

[46] D. E. Hooks, T. Fritz, M. D. Ward, Adv. Mat. 2001, 13, 227.

[47] T. Laino, F. Mohamed, A. Laio, M. Parrinello, J. Chem. Theory Comput. 2005, 1, 1176

[48] T. Laino, F. Mohamed, A. Laio, M. Parrinello, J. Chem. Theory Comput. 2006, 2, 1370.

[49] W. Liu, J. Carrasco, B. Santra, A. Michaelides, M. Scheffler, A. Tkatchenko, Phys. Rev. B 2012, 86, 245405.

[50] F. W. de Wette, W. Kress, U. Schröder, Phys. Rev. B 1985, 32, 4143.

[51] J. Vogt, H. Weiss, Surf. Sci. 2001, 491, 155. 
[52] K. K. Diwedi, M. K. Diwedi, S. N. Tiwari, J. Cryst. Proc. Technol. 2014, $4,31$.

[53] M. O. Sinnokrot, E. F. Valeev, C. D. Sherrill, J. Am. Chem. Soc. 2002, 124, 10887.

[54] J. M. Sanders, J. Phys. Chem. 2010, 114, 9205.

[55] S. E. Wheeler, Acc. Chem. Res. 2013, 46, 1029.

[56] C. R. Martinez, B. L. Iverson, Chem. Sci. 2012, 3, 2192.

[57] F. Federici Canova, A. S. Foster, M. L. Rasmussen, M. Meinander, F. Besenbacher, J. V. Lauristen, Nanotechnology 2012, 23, 1.

[58] D. Z. Gao, J. Grenz, M. B. Watkins, F. Federici Canova, A. Schwarz, R. Wiesendanger, A. L. Shluger, ACS Nano 2014, 8, 5338.

[59] I. Horcas, R. Fernandez, J. M. Gomez-Rodriguez, J. Colchero, J. Gomez-Herrero, A. M. Baro, Rev. Sci. Instrum. 2007, 78, 013705.

[60] F. J. Giessibl, Phys. Rev. B 1997, 56, 16010.
[61] B. Anczykowski, B. Gotsmann, H. Fuchs, J. P. Cleveland, V. B. Elings, Appl. Surf. Sci. 1999, 140, 376.

[62] G. Lippert, J. Hutter, M. Parrinello, M. M. Mol. Phys. 1997, 92, 447.

[63] J. VandeVondele, M. Krack, F. Mohamed, M. Parrinello, T. Chassaing, J. Hutter, Comput. Phys. Commun. 2005, 167, 103.

[64] S. Grimme, J. Comput. Chem. 2006, 27, 1787.

[65] J. VandeVondele, J. Hutter, J. Chem. Phys. 2007, 127, 114105.

[66] C. R. A. Catlow, K. M. Diller, M. J. Norgett, J. Phys. C: Solid State Phys. 1977, 10, 1395.

[67] D. Z. Gao, F. Federici-Canova, M. B. Watkins, A. L. Shluger, unpublished.

[68] H. Jennet, H. Bubert, E. Grallath, Fres. Z. Anal. Chem.333, 502.

[69] M. C. McCarthy, F. Tamassia, D. E. Woon, P. A. Thaddeus, J. Chem. Phys. 2008, 129, 184301 